\title{
PSYCHE
}

VOL. XXX.

FEBRUARY 1923

No. 1

\section{THE OCCURENCE OF MUSCINA PASCUORUM MEIGEN IN NORTH AMERICA IN 1922. ${ }^{1}$}

(Presented Dec. 26, 1922, at the Boston meeting of the Entomological Society of America.)

By Charles W. Johnson.

Boston Society of Natural History.

The increase and spread of this European fly in such numbers and over so wide an area, before its presence was actually discovered, was a great surprise, especially to the dipterist. The first specimens to come under my observation were received on October 10, among some Diptera collected by Dr. W. M. Wheeler, at Colebrook, Connecticut. The three specimens were taken, August 10, 18 and 21. A few days later I received a box of flies from Mr. K. F. Chamberlain, of Cornwall Bridge, Conn., and among them was a specimen collected August 6, the earliest record I have for the species. Mr. R. T. Webber found among the material collected at the Bound Brook nurseries, N. J., a specimen taken September 1. Professor C. T. Brues observed it in numbers both in his house and about a neighboring cider mill at Petersham, Mass., October 8. Mr. F. H. Walker collected two specimens at Marblehead, Mass., October 15. A few days later I received five specimens from Mrs. Ella L. Horr of the Worcester Natural History Society. Mrs. Horr said they were abundant in the cupola of the building and that the janitor said they were there in September, but that she did not happen to go there until about October 21. I wrote her that the fly was new to me and that I should like very much to have some more specimens. No males had been seen and I was doubtful in which of two European species to place it. On October 25, Mrs. Horr wrote to me that she had sent some to Washington and on the 26 th sent me 51 specimens. I wrote to Dr. J. M. Aldrich in 
regard to the matter and on November 1 he replied as follows "It is Muscina pascuorum Meigen. I have compared it with European specimens determined by several authorities, and hence there is no doubt of what it is."

On October 27 I took two specimens on the window at my home in Brookline and on the 31st I received several specimens from Mrs. L. C. Marshall, of East Walpole, who said they were abundant in her house. On November 1, Dr. G. M. Allen captured a specimen in his house in Cambridge. On the $3 \mathrm{~d}$ Dr. F. T. Lewis brought in seven specimens taken at Waban, Newton, and on the same date Dr. J. A. Cushman collected a specimen at Sharon. On the 7 th a specimen was taken on a window at the Boston Society of Natural History, and on the 8th Dr. Lewis took a specimen at the Harvard Medical School, Boston. Thes single specimens indicate that they were by no means common in the city. On the 7th Dr. Cushman collected at Sharon nine specimens, among which was a male, the first I had seen. Dr Cushman then made three collections at Sharon, which are interesting in showing the relative proportion of this and the other species that normally frequent houses in the autumn.

November 12, 46 Muscina pascuorum (all females), $30 \mathrm{M}$. assimilis, 19 Pollenia rudis, 10 Phormia regina, 1 Cynomyia cadavorina. and 1 Musca domestica.

November 16, $22 M$. pascuorum, $12 M$. assimilis, $15 P$ rudis, and $2 P$. regina.

November 26, 13 M. pascuorum, 11 P. rudis, and 5 P. regina

Another interesting series showing the relative abundanc of this species was made by Mr. F. H. Walker in the attic of a summer cottage at Asbury Grove, Mass. November 9, he collected 275 Muscina pascuorum (2 males), 21 Pollenia rudis, 15 Phormia regina, and $1 M$. assimilis. Mr. Walker says: "I could have obtained thousands from neighboring cottages. The skylight from which I obtained these flies measured 22 by 36 inches."

The following additional records show how abundant and generally distributed the species is throughout eastern Massa- 
chusetts On November $10 \mathrm{Mr}$. M. T. Smulyan took a specimen at Melrose Highlands; on the 11th Mr. A. P. Morse captured a number at Ipswich; and on the 12th at Wellesley. On the 13th Mr. W. L. Maxcy reported it as abundant in his house at Stillwater. On the 14th I caught the second male on a window in Brookline, and on the same date Mr. R. T. Webber reported it from Dover, and Mr. G. W. Barber from Arlington. On the 15th Miss Margaret Hayden collected it at Ashland; on the 18th Mr. C. V. Blackburn obtained it at Stoneham; on the 19th Mr. L. W. Jenkins secured it at Putnamville. On the 30th Mr. S. N. F. Sanford caught a specimen at Fall River, and on Dec. 2 Dr. G. M. Allen captured two at Cohasset.

Correspondence, together with a note published in Science (November 24), has further added to our knowledge of its distribution. Under date of November 14, Dr. W. E. Britton, of the Connecticut Agricultural Experiment Station, New Haven, writes: "We have noticed a number of large-sized flies around the windows and have killed some of them. We paid little attention to the species, but there are now some dead ones around the place and I will have some of them relaxed, pinned, and sent to you." I received the flies, November 21 and they were all $M$. pascuorum. Dr. H. T. Fernald, of Amherst, Mass., writes, "Answering your letter of Nov. 17, I may say that we have noticed a species of Muscina on our windows this fall and took specimens first on Oct. 12, though they were present considerably before that date. We are referring it to Muscina pabulorum Meig. I should be very glad to know whether we are on the right track." Under date of November 28, Dr. Fernald again writes: "Many thanks for your letter of Nov. 27. It has been reasonably abundant here, and was certainly present for at least a week or ten days before we thought of taking and actually dating a specimen. I have not heard of it from any other part of the state mainly because nobody appears to pay any attention to flies which show up on house windows."

In a letter from Dr. O. A. Johannsen of Ithaca, N. Y., dated November 24, he says:- 
"I saw your note in Science this evening with regard to Muscina pascuorum and hasten to state that in Ithaca we have just discovered a new Muscina. Tuesday of this week I caught a fly in my laboratory which looked like $M$. slabulans but with black legs. As I was busy with other things I thought no more about it until the next day when Mr. Raymond C. Shannon came in with a fly which he asked me to look at. He realized that it was not one of the two species of Muscinas which were prevalent here. Mr. Shannon has been taking this species in Ithaca now for several days and he told me that there is one (either in his own or in the University collection, I have forgotten which) which was caught here in September. We tried to identify it and reached the conclusion that it was either pabulorum or pascuorum."

Later Mr. Shannon wrote: "My captures of Muscina pascuorum consist of nine females and one male, collected from September 5 to November 22. "On December 16 Jos. C. Ouellet, C. S. V. of Outremont, Quebec, writes:--"I have just received from Father Ducharme of Rigaud College, a specimen which closely resembles Muscina pascuorum. I am mailing you the specimen today." The specimen was received on the 20 th and proved to be a male of that species and the most northern record.

Over 450 specimens have come under my observation and of these only ten were males. A natural inference is, that this is probably due to their having been discovered so late in the season, and that it is usually the female that comes into the houses to hibernate. On the other hand it was not until November 7 that I saw a male, after over 90 specimens had been seen, and Dr. Wheeler informs me that the specimens he collected in August were taken on flowers.

I can find very little in literature pertaining to the habits of this species. Schiner (Fauna Austriaca, I, 597) says that "Bremi found the larvæ in Agaricus citrinus." On making some inquiry regarding the fungi found in the vicinity of Boston, Miss Jennie F. Conant, Secretary of the Boston Mycologial Club, informed me that this is the same as Amanita citrina, common to both 
Europe and North America. It is found from August to early November, and some of the members of the Club say that it was quite common this year. Charles McIlvaine (One thousand American Fungi, p.7. 1900) considers it only a form of A. phalloides. Miss Conant also reported a number of other species of Amanita, including $A$. phalloides, as being common, and as early as July. If Muscina pascuorum is strictly fungicolous, the abundance of these fungi might account for the rapid increase of this fly during the autumn.

The wide distribution that this fly has attained in this country before being discovered, makes it difficult to ascertain where the species was actually introduced. The prezence of the fly in Connecticut and New Jersey at least two months before being observed in the vicinity of Boston, is an indication that it was probably introduced somewhere near New York City, sometime prior to the present year (1922). This theory is strengthened by the usual or apparently natural line of dispersal of species in a northerly or northeasterly direction, as followed by most of the introduced species; e.g., elm beetle, asparagus beetles, leopard moth, gipsy moth, etc.

Its present distribution would indicate a still wider dispersal if all records were available. Its habit of entering houses would also induce it to enter railroad cars and thus be rapidly and widely transported over the country, a factor that probably partly accounts for its sudden and wide-spread appearance. It promises to be as great a nuisance to housekeepers as the cluster fly (Pollenia rudis) which often enters houses in great numbers in the autumn. The last living specimen of Muscina pascuorum was received from Dr. Lewis, Waban, Mass., December 14. It will probably continue to appear in lesser numbers during the warm days throughout the winter and spring. A study of its habits and dispersal during the coming year will prove very interesting. 

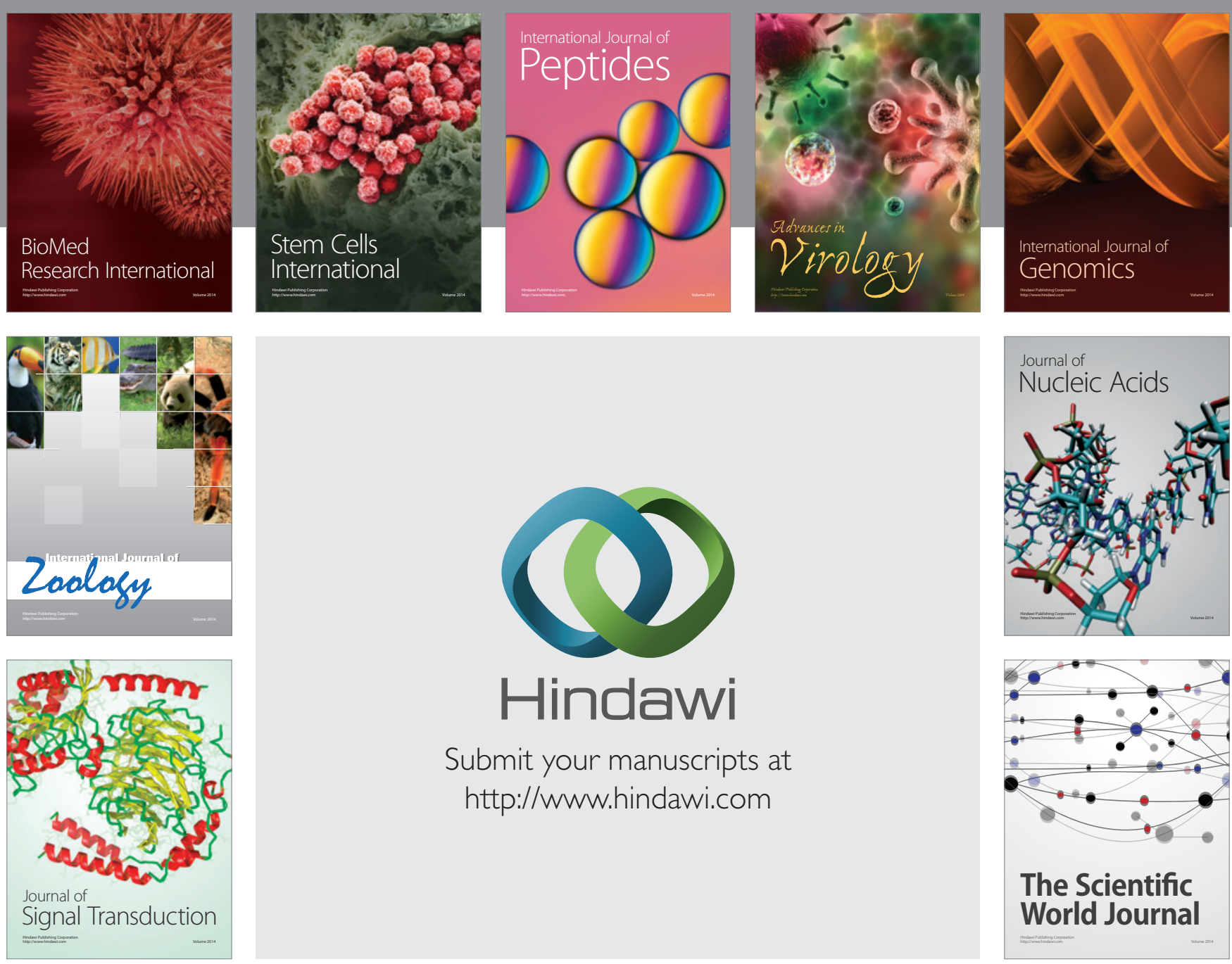

Submit your manuscripts at

http://www.hindawi.com
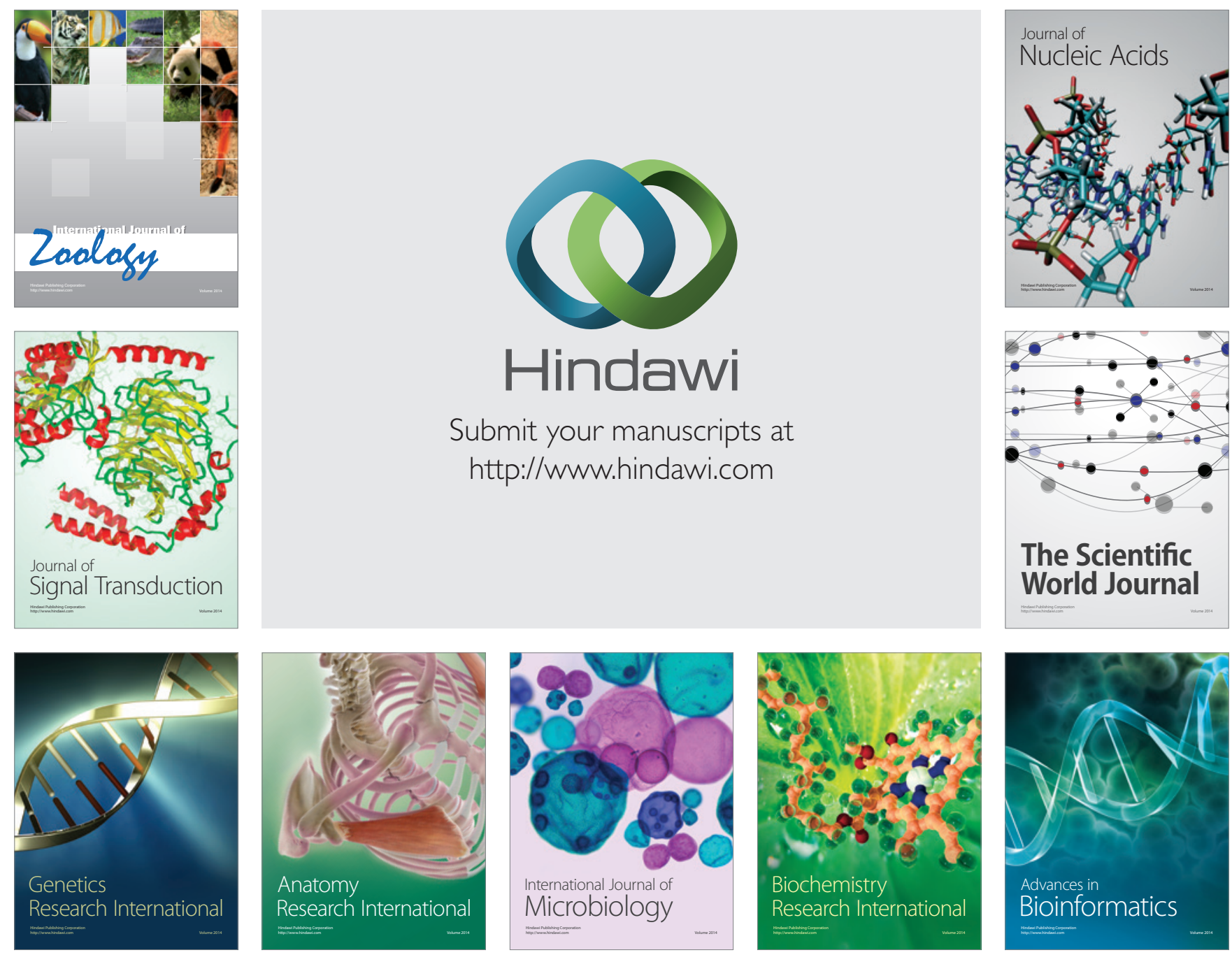

The Scientific World Journal
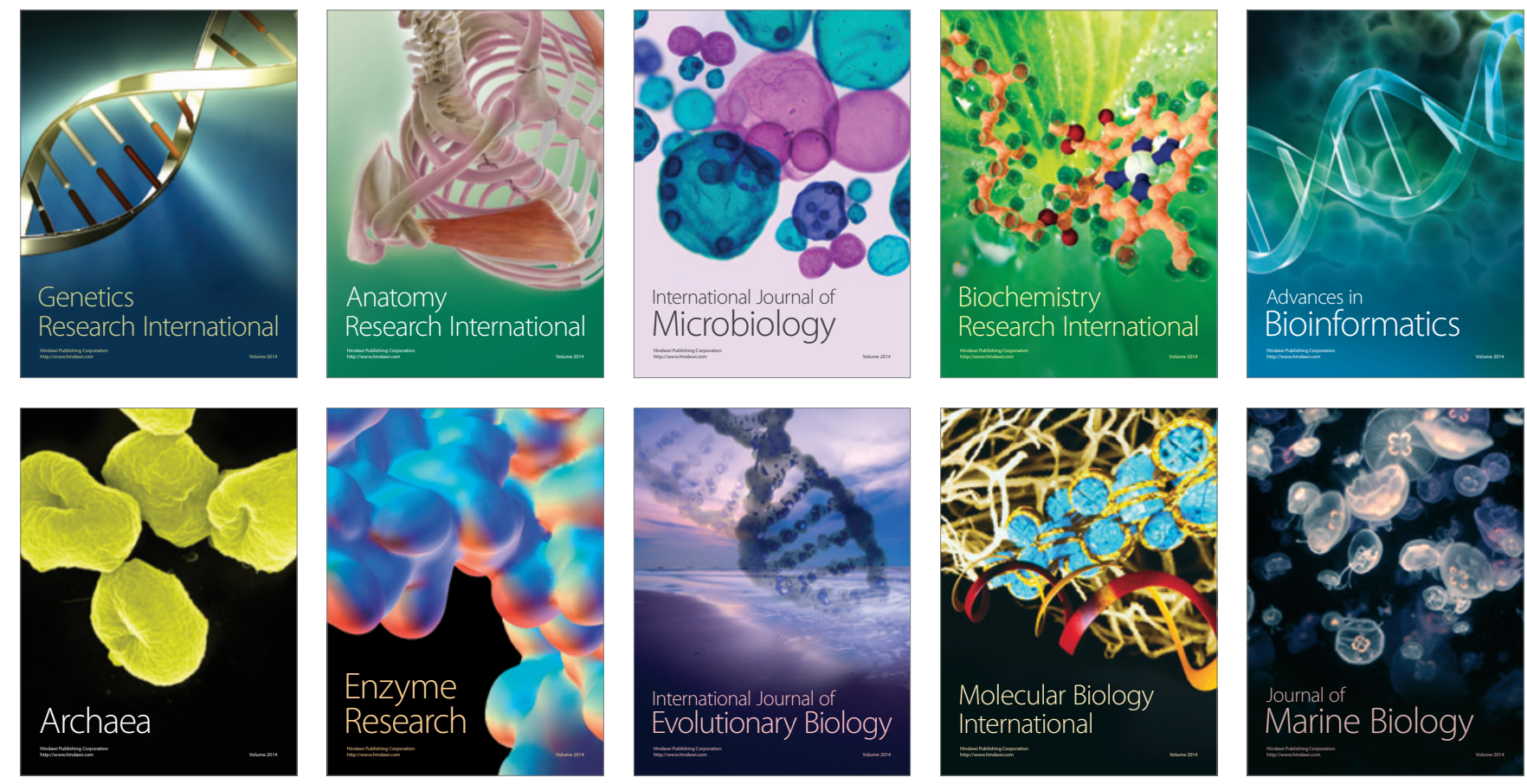